Article

\title{
Cryptourbanomics: A Method to Boost Urban Sustainability with Blockchain Technology
}

\author{
Maria-Luisa Marsal-Llacuna
}

Citation: Marsal-Llacuna, M.-L. Cryptourbanomics: A Method to Boost Urban Sustainability with Blockchain Technology. Sustainability 2021, 13, 2438. https://doi.org/ $10.3390 /$ su13052438

Academic Editor: Tan Yigitcanlar

Received: 29 December 2020

Accepted: 17 February 2021

Published: 24 February 2021

Publisher's Note: MDPI stays neutral with regard to jurisdictional claims in published maps and institutional affiliations.

Copyright: (C) 2021 by the author. Licensee MDPI, Basel, Switzerland. This article is an open access article distributed under the terms and conditions of the Creative Commons Attribution (CC BY) license (https:// creativecommons.org/licenses/by/ $4.0 /)$.
Intelligenter Research Association, 08712 Barcelona, Spain; 1lmarsal@intelligenter.org

\begin{abstract}
Cryptourbanomics puts forward the idea that there are forces and capital in our society that cannot be dismissed or neglected but that the System (understood as the Establishment or Status-quo) has failed to acknowledge or been unable to address. These social forces have strong ideological, cultural, or identity components, sometimes related to an unrealized Right to the City (Lefèvre, 1968). The social capital behind those forces are often citizens who gave up-the so-called dropouts because they lost their faith in the System and prefer living in their own world. Blockchain is the technology that empowers these unheard social forces and capital. However, blockchain will remain as an Anti-System technology until it finds a fit within the Establishment until the Status-quo acknowledges and ushers it. Cryptourbanomics is a novel method that brings into the blockchain those societal challenges that the System leaves unsolved. And because today's societal challenges mostly take place in urban environments, the Cryptourbanomics method focuses on the overall urban sustainability and analyses them with a blockchain lens. The Cryptourbanomics method includes an array of blockchain tools to tackle legacy societal challenges yet unsolved by the System with a more decentralised, distributed, transparent and neutral approach. This paper shows how the Cryptourbanomics method can help deliver on Urban Sustainability by shifting powers, from the Establishment to Communities, and it showcases this with a use case within the Right to the City, that is the Right to Work.
\end{abstract}

Keywords: blockchain; sustainability; decentralised governance; distributed networks; power disruption

\section{Introduction}

Blockchain technologies can deliver on the promise of a more citizen-centric society since blockchain technologies are bottom-up-led by design and rely on a peer-to-peer network of individuals. Blockchain technology is typically defined as a peer-to-peer decentralised and distributed network of nodes seemingly securing transactions on a largely replicated ledger. Accordingly, a blockchain is disintermediated since users (peers) operate directly with other network users without the need for a middleman or central authority to grant them access. And are precisely these two features of distribution and decentralisation what makes blockchain a disruptive technology.

However, methodologies need to be developed to effectively use blockchain technology in real-world situations. Cryptourbanomics offers a method to use blockchain in tackling real-world challenges that the System has been unable to solve with traditional legacy mechanisms such as urban strategies, policies, planning, and regulations. Blockchain is still an immature technology and meaningful real-world use cases are scarce, hence the importance of methods like Cryptourbanomics that help its implementation. Although some authors argue that the philosophy that exists around blockchain makes it a mature technology [1] it is widely accepted that blockchain technology is in its infancy, being at the development stage that the web was in 1992, thus with lots crises and hypes yet to come. In any event, the System has not even acknowledged blockchain as a technology. Within the System, only a couple of genuine projects are relevant. These are the government-led blockchain platforms of Dubai and Illinois [2]. On the other hand, the 
System is experimenting with the technology by transfiguring and adapting it so that it can be controlled, resulting in the so-called "enterprise blockchain", which is not an actual blockchain but a different technology, that is private and/or permissioned distributed ledgers (DLT). This poor usage of blockchain technology by the System leaves blockchain as an anti-System technology since it is being mostly developed and used outside the System and will continue like this until governments and the private sector start using it for daily transactions, and in its genuine form, without transforming it into a different technology. But this is a chicken and egg situation because, when asked, the public sector says that they are not using the technology because the private sector is not offering them blockchain solutions that help them deal with real-world problems. And the industry recognises that genuine blockchain technology (such as Bitcoin or Ethereum) harms their businesses because it puts into question the need for many of their services. The only way to allow for blockchain technology to be present in our daily lives is for the System to embrace it and this will happen when the industry puts efforts and resources into creating the interfaces that will allow administrations to offer blockchain-based services to citizens. When this happens, citizens who use genuine blockchain technology will not feel like the anti-System and cyberpunk guys anymore.

The Cryptourbanomics method specifically looks at real-world implementations that will solve those legacy societal challenges that traditional mechanisms could not. Traditional codes to tackle societal challenges include strategies, policies, planning, and regulations. The novel findings of the Cryptourbanomics method unveil specific blockchain code that can help deliver traditional codes in a more decentralised, distributed, transparent and disruptive manner. Indeed, blockchain codes such as transactions, tokens, crowd-sales, and decentralised autonomous organisations can be paired with traditional codes to tackle those unsolved legacy challenges with a community-based and citizen-centred perspective. Thus, the Cryptourbanomics method can be summarised as a governance model to tackle people's unsolved challenges by the people and from the people. If a Cryptourbanomics implementation has no involvement from the public and/or private sectors it will be called a "bottom-only" solution whereas, if there is participation from the System it will be a "bottom-up" solution. As part of the state-of-the-art of the Cryptourbanomics method, thorough research has been conducted to find references and concepts close to the Crytpourbanomics pursuit. The closest were the works of Huckle and White [3], where they suggest a utopian-socialist-kind-of community concept where the division of classes dissipates. This lack of methods using blockchain makes the Cryptourbanomics contribution even more valuable.

The Cryptourbanomics method consists of 4 components, which are briefly outlined in Figure 1. Depending on the nature and complexity of the challenge all 4 components might be required or, on the contrary, just the initial ones. The following sections of the paper describe each of the components. Special attention has been placed on showcasing the pairing between the common elements that can be found in legacy codes as well as in blockchain code. These common elements will make it possible to align traditional mechanisms with novel blockchain tools and thus tackle real-world challenges differently. The four pairs "legacy codes + blockchain code" are displayed one per row in Figure 1 in the second and third columns respectively. The first column of the table shows blockchain characteristics, dully organised in correspondence with the most relevant blockchain tool serving that characteristic (column 3). Finally, the fourth and fifth column describes the cause stage that each of the pairs can tackle and the resulting effect of implementing such a pair. It is therefore important to properly identify the cause stage being tackled to use the right pair and no more. In other words, using a too complex pair to solve a simple challenge (e.g., designing a cause by "creating an organisation to draft new regulations") will not work as it will unnecessarily overcomplicate the challenge and lose track of it. Lastly, to briefly introduce to the reader the boxes placed in each row in the first and second/third column, before they are described in full detail in the following sections. Boxes in the first column show the subordinate blockchain characteristics resulting from paring real-world 
codes (legacy codes) with blockchain code. Cryptourbanomics has found out that when blockchain characteristics enter in contact with real-world situations, these evolve and mutate slightly. Boxes in the second/third column show an older technology that allows to bridge the connection between legacy codes and blockchain code and thus establish each of the pairings.

The Cryptourbanomics model

\begin{tabular}{|c|c|c|c|c|}
\hline $\begin{array}{c}\text { Blockchain } \\
\text { characteristics }\end{array}$ & $\begin{array}{l}\text { Legacy } \\
\text { codes }\end{array}$ & $\begin{array}{l}\text { Blockchain } \\
\text { code }\end{array}$ & $\begin{array}{l}\text { Cause } \\
\text { stage }\end{array}$ & $\begin{array}{l}\text { Implementation } \\
\text { effect }\end{array}$ \\
\hline Disintermediation & Strategies & Transactions & \multirow[t]{2}{*}{ selecting a challenge } & \multirow[t]{2}{*}{ self-sufficiency } \\
\hline Devolution & \multicolumn{2}{|c|}{ cellular automata } & & \\
\hline Disruption & Policies & Tokens & \multirow[t]{2}{*}{ designing the cause } & \multirow[t]{2}{*}{ empowering } \\
\hline Diversity & \multicolumn{2}{|c|}{ complex systems } & & \\
\hline Distribution & Planning & Crowd-sales & implementing the & \multirow[t]{2}{*}{ managing } \\
\hline Granularity & \multicolumn{2}{|c|}{ state machines } & cause & \\
\hline Decentralisation & Regulations & Organisations & governing the cause & \multirow[t]{2}{*}{ self-governance } \\
\hline Levelling & \multicolumn{2}{|c|}{ notational combinatorics } & & \\
\hline
\end{tabular}

Figure 1. Components of the Cryptourbanomics method.

\section{Disintermediating Strategies with a Simple Blockchain Transaction: The Public Agora Dashboard as Example}

The dashboard of Urban Sustainability is commonly defined in the literature as having three axes, the economic, the social and the environmental pillars. These pillars, all equally important, will define the dashboard structure of the Cryptourabnomics method, which relies on blockchain transactions to implement its disintermediated steering capabilities.

Perhaps basic challenges remain unsolved because there is not the right middleman to address them or simply it is not interesting for intermediaries to get them solved. Whatever is the case, the reality is that there are very important and at the same time essential realworld challenges that remain unsolved. Quoting Buckminster Fuller back in 1980, “Think of it. We are blessed with technology that would be indescribable to our forefathers. We have the wherewithal, the know-it-all, to feed everybody, clothe everybody, give every human on earth a chance. We know now what we could never have known before-that we now have an option for all humanity to "make it" successfully on this planet in this lifetime. Whether it is to be Utopia or Oblivion will be a touch-and-go relay race right up to the final moment." Almost forty years later we still can find poverty in most cities or even in entire countries, citizens fleeing war and hunger, and crime and violence. These are just some of the very important challenges that we still face but the list is much larger. Of course, the System tried solving these problems with their traditional codes, mostly by implementing a Strategy that sometimes it even evolved towards a Policy, delivered through Planning governed by a Regulations. This is what we could call the "traditional problem-solving chain of codes". What the different steps in this legacy chain have in common is that their execution is subcontracted to intermediaries with little or no participation from the beneficiary or end-user, that is the citizen. Currently, participatory processes in policy drafting, master planning, and the passing of regulations are limited to, at most, public consultation taking place at the very end of the process. In other words, the citizen is used as a validator but not as a designer. The author of this paper has largely published about this issue [4-6]. Would not all of these Strategies, Policies, Plans, and Regulations better cover citizens' needs if citizens would be directly involved in the design process? The answer is yes.

Until 2008 the only technology available to include the citizen in the creation process of a given code were consultations and surveys that, unfortunately, take place too late in the process and therefore can only have a validation input. However, since 2008 we have blockchain technology, pioneered by Bitcoin. Blockchain technology does not only 
allow for active participation of the citizen but empowers the whole Community to tackle challenges by themselves without the need for a central authority (such as the System) to trigger the "problem-solving chain of codes". The fact that blockchain is a peer-to-peer distributed and decentralised technology allows for the Community to get organised and transact directly, thus it also eliminates the need for middlemen participation. As mentioned earlier, this community-based approach to problem-solving making use of blockchain technology is what under the Cryptourbanomics method is called the "bottomonly" approach. However, if the System is part of the Community, which is the most desirable situation as we will see later in the article, the approach is called "bottom-up". In this section, we will show how a simple blockchain transaction allows for communityled Strategies thanks to blockchain disintermediation capabilities and how this simple blockchain transaction suffices to address the most essential and basic challenges. This simplicity is in stark contrast with the legacy System needing to implement the whole "traditional problem-solving chain of codes" and yet not solving basic challenges.

Let us first understand what a disintermediated Strategy is by looking at one of the earliest and few examples we can find in urban history. In 1391, the Catalan Francesc Eiximenis (Girona 1335-Perpignan 1409) solved a social rebellion by making use of a disintermediated Strategy. Eiximenis works include a number of treaties. Most of his works were written in Valencia, where he stayed from 1382 to 1408 . There he was a consultant to the "Jurats" (city representatives organised as jury) and to the "Consell" (ruling organ of the city). 1391 was a very difficult year for the city and kingdom of Valencia since there were many social problems. Eiximenis organized a kind of "people's army" in some monasteries and convents around Valencia to tackle social unrest, instead of using traditional military brute force. This is one of the few examples we can find in the history of disintermediation in favour of Communities. His "Disintermediated Strategy" circulated the world. He even wrote two letters in 1392 and 1396 at the request of King Martin I, advising him on how to engage with citizens to improve city government in Sicily. His treaty Regiment de la Cosa Pública (1383), published as book in 1499 [7], collects Eiximenis principles for good governance through disintermediation (see Figure 2). As seen with the social unrest situation that made his Strategy famous, good governance has to disintermediate as much as possible in favour of the people, what we call today "devolution". Nowadays, devolution principles are used by administrations to devolve to lower administrative levels (e.g., from national governments to local councils).

Transparent execution and limited and controlled transferring of competences are what guided Eiximenis back then on how to disintermediate Strategies and devolve to people. And this is exactly how disintermediation works in a blockchain network, by devolving what it is typically handled by middleman positions to the network community using controlled mechanical instrumentation. This tooling is what is known as a Turing machine. Now that we know how disintermediation and devolution work for real-world Strategies let us learn how a Turing machine does it for the blockchain so that we can later pair both elements. In essence, a Turing machine is anything that can be computed by an algorithm. A Turing machine is a mathematical model of computation that defines an abstract machine, which manipulates symbols on a strip of tape according to a table of rules. Despite the simplicity of the model, given any computer algorithm, a Turing machine is capable of simulating that algorithm's logic so that it can be built. Using his coding skills and knowledge of cypher technologies, Alan Turing designed what would become the first Turing machine to decode the Engima code, created by the Germans during WWII. His help was decisive for the Allies to win the war. Turing also answered what was known as the "Halting problem". Questions like: Do a certain set of premises entail a given conclusion? Is there an automatic way of finding out whether they do or do not? These questions remained unanswered until Turing's studies on algorithms. Turing was the first to prove that with first-order logic (mathematics) you cannot reply to these questions. In other words, you cannot predict whether your computer programme will halt (known as Turing completeness) or run forever (Turing incompleteness). 


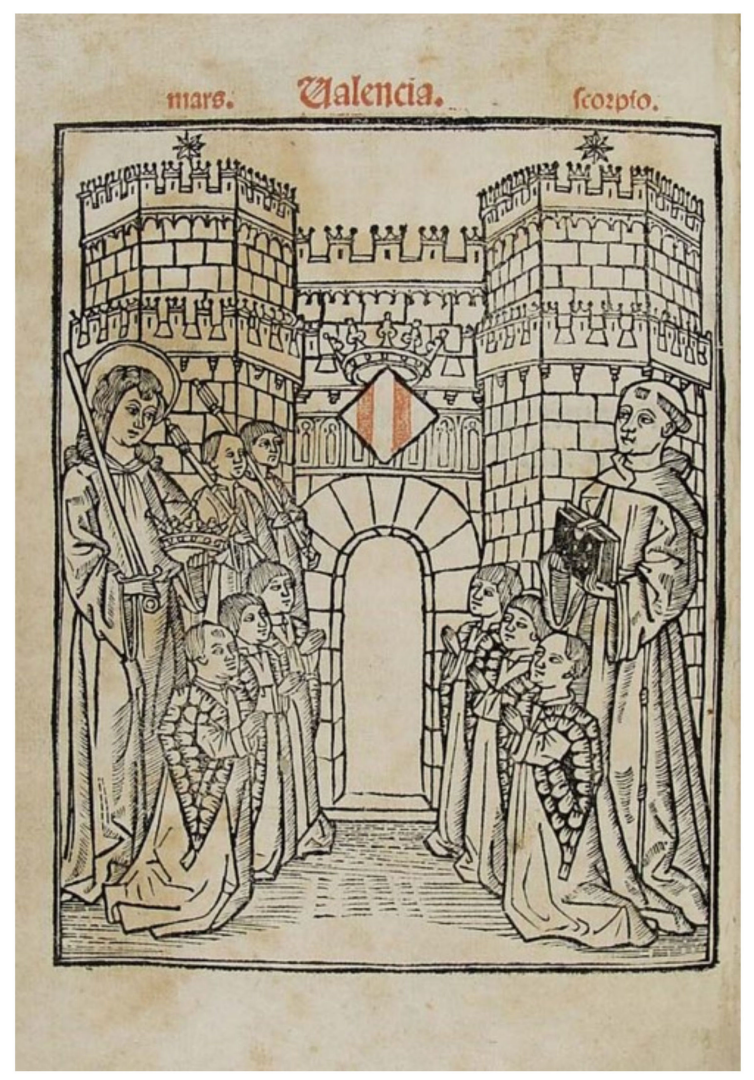

Figure 2. Front cover of Regiment de la Cosa Pública. On the left, we can see Eiximenis offering his book to the "Consell", one of the earliest examples of disintermediation. Source: https:/ / commons. wikimedia.org/wiki/File:Regiment_de_la_Cosa_Publica.jpg (accessed on 22 February 2021).

Now the question for blockchain technology is, since the two most prominent blockchains, Bitcoin and Ethereum, both can run programmes and therefore compute algorithms, why do we say that Bitcoin is not Turing complete whereas Ethereum is? The difference lays in how these two blockchains deal with the Halting problem. In Bitcoin infinite loops are not intrinsically solved within the computation instance, the transaction (Tx). This means that a Bitcoin programme could run forever if there would not be flow controls external to the computation instance to prevent those infinite loops. This is why, in Bitcoin, a Tx pays fees according to its size. In Ethereum, infinite loops are solved intrinsically to the computation instance or transaction with the "gas". If an Ethereum Tx is a contract, the gas will automatically end the contract when it runs out of it. However, some experts argue that Ethereum is almost Turing complete since contracts are bounded to block validation time, thus depending on external flow control. Turing completeness and incompleteness in Bitcoin and Ethereum can be simplified by saying that whereas the Bitcoin blockchain has to "decide" whether or not ending a Tx because fees are not sufficient to terminate its operations, in the Ethereum blockchain there is no such "decision-making" thanks to the gas. In any event, everyone will agree that an Ethereum non-contract Tx is Turing complete. An Ethereum non-contract Tx will send data or currency to another account and its deployment occurs within the same Tx, spanning a single block. Let us understand this by comparing a non-contract $\mathrm{Tx}$ with a one-dimensional cellular automaton which is the simplest example of code considered to be Turing complete [8].

A cellular automaton consists of an iterative grid of cells and each cell is one of a finite number of states, such as on and off. The grid can have any finite number of dimensions. For each cell, a set of cells around it are called its "neighbourhood". An initial state (time $t=0$ ) is selected by assigning a state for each cell. A new generation is created (advancing t by 1), according to some fixed rule (generally, a mathematical function) that determines the new state of each cell in terms of the current state of the cell and the states of 
the cells in its neighbourhood. Typically, the rule for updating the state of cells is the same for each cell and does not change over time and is applied to the whole grid simultaneously. A very well-known example of a cellular automata is the Game of Life [9]. It is a zero-player game meaning that its evolution is determined by its initial state, requiring no further input. One interacts with the game creating an initial configuration and observing how it evolves, or, for advanced players, by creating patterns with particular properties. The automaton in an Eth non-contract Tx consists of a user input that will result in automated outputs. Txs are made up of inputs and outputs. Inputs are references to outputs of earlier transactions. Inputs meet the requirements that the output was encumbered with, and they supply value to the transaction. Outputs encumber that value with requirements that must be met for that output to be used as an input to another transaction.

Unspent Transaction Outputs (UTXO) are a list of the outputs which a node has not yet seen used as an input. When an output in the UTXO is seen as an input to a transaction, the node removes that output from its UTXO so that any other transaction trying to use it as an input will be identified as invalid. Every output will consist of a guarding script and a payload, while input is a reference to an output from a previous Tx. The current state of the automaton is stored in Tx output's payload. The general idea is that the next Tx is a single step of automaton's evolution. This will be always true if two conditions are satisfied: (1) the payload of at least one newly generated output should contain the updated state of the automaton. (2) this output must contain exactly the same script. These conditions require Tx input to have access to the output's scripts and payloads. With this script, the cellular automaton evolution can be started by chaining an initial Tx to the blockchain. Cellular automatons are implicitly present in the vast majority of existing blockchains since, in most cases, scripts verify the signature of the spending Tx, which is constructed over the byte array containing the new outputs [10]. The two conditions mentioned earlier require the script to performs two checks: (1) it takes the payload of a current input and ensures that the result of the automata equals the payload of the first output. (2) it checks that the guarding script of the first output is the same script of the input. Infinite evolution of a cellular automaton, which is required but not sufficient for Turing completeness, can be modelled by chaining a potentially infinite number of $\mathrm{Tx}$ in the blockchain. However, infinite automata evolution requires that both sizes of the data stored in output and Tx validation time have an upper bound, otherwise the blockchain would be losing its security properties. The natural workaround is to split the automaton state between Tx once it becomes too large so that the blockchain can have a potentially infinite evolution in space and time.

If we now join the dots of Turing completeness and cellular automaton, we will understand why the Cryptourbanomics method understands Ethereum's non-contract Txs as the ideal tool for disintermediated Strategies. As seen earlier, non-contract Txs are a Turing complete cellular automaton, which means that its evolution within the blockchain is potentially infinite in time and space. Turing completeness is given by the "gas" boundaries, what turns the Tx into a very limited and contained instrument, ideal to disintermediate in favour of end-users and devolve competences to them in a very controlled and restrained fashion. Of course, as seen with Eiximenis, we cannot forget about transparent execution when devolving and disintermediating. In public blockchains, such as Bitcoin and Ethereum, this is taken care of with Tx mining. Turing completeness of non-contract Txs can only be achieved by attaching Txs to the blockchain so that Txs can behave as cellular automaton. This requires blockchain mining. Mining is a self-reproducing coins rewards system used by blockchains that ensures attachment of Txs in blocks and these into the chain. This means that any structure willing to empower subordinate structures through disintermediated Strategies and devolution can only rely on public blockchains, otherwise, they will not enjoy the full seamless and real-time settlement provided by public blockchains. And, more importantly, in public blockchains, Txs are transparent and accessible to everyone. 
To illustrate how the Cyptourbanomics method works when it comes to implementing the Public Agora Dashboard, which is the tool that empowers communities by helping them to disintermediate strategies, a use case on the Right to Work and specifically on how the method can help end youth unemployment is included here. A project based on the Cryptourbanomics method begins with disintermediation, that is empowering communities to self-solve their challenges and uses blockchain transactions as a tool. Let us say a community has identified youth unemployment as a challenge unresolved by the System and want to tackle it in a bottom-up fashion. They will begin by setting up their community on the Public Agora Dashboard's website and registering all interested parties, that is unemployed and potential employers. Similar to what social media tools do, these two groups will be connected and job candidates will be put in contact with their potential employers when there is a match. Once the match is agreed off-chain, both parties will be asked to create an account on the Cryptourbanomics blockchain -which will be their on-chain identity- and to send each other a transaction as proof-of-agreement. This transaction is the beginning of the whole collaboration between parties which will be exclusively handled on-chain. In the following sections, the next steps of this collaboration will be explained and exemplified using this very same use case.

\section{Disruptive Policies Made Possible with Tokenisation: The Example of the Ars Local Cryptocurrency}

The first pillar of Urban Sustainability is Ecology. In this section, it will be presented how the Cryptourbanomics Method helps deliver on environmental sustainability by relying on blockchain capabilities to disrupt environments with the introduction of new local economies. With that purpose, we will revisit Ramon Margalef's mathematical models to study behaviour and communication in populations of species and learn how these naturally disrupt their environments.

It is commonly said that blockchain technology is disruptive. Disruption is a consequence of the technology being a disintermediation tool, allowing for peer-to-peer transactions without the need of a third party performing the transaction for us. But, is precisely this disruptive nature of blockchains what causes a lot of misunderstanding around the technology. Middlemen services are afraid about blockchains' disruptive capabilities and, unable to reposition their services in this distributed and decentralised environment they are opting for "pretending" they are embracing the technology when, in reality, they are just using a different technology that is distributed, yes, but not decentralised at all since this would go against their business interests. This non-decentralised version of distributed technologies are the so-called Distributed Ledgers (DLTs). Thus, this means blockchain disruptive capabilities are relevant and it is, therefore, worth understanding them in full. In this section blockchain, disruption will be explained in detail. The blockchain tool acknowledged as having the most disruptive effect are the tokens. The Cryptourbanomics method pairs the tokens with the most disruptive legacy tool within the legacy codes, that is Policies and we will use complex system principles to establish the pairing (see Figure 1). Policies are the instrument within our legacy codes (Strategies, Policies, Planning and Regulations) understood as being the most flexible, creative, capable of introducing innovation and therefore, disruptive.

Disruption in Communities occurs when their species are close to instability. This introduces complexity and evolution of Communities. Therefore, to understand disruption we have to study evolutionary and ecological complex systems. Ramon Margalef was the first scientist to model disruption in Communities and found out that disruption begins with diversity. This means that without diversity there is no disruption. In his seminal book, Perspectives in Ecological Theory [11] provides the foundations to understand evolutionary and ecological complex systems. Blockchains are certainly not an ecological system but a communications system and, as such, are an evolutionary one. However, some authors sustain that blockchains are not complex systems [12] while others [13] argue they are because are often used to orchestrate ecological systems, as proven by the multiple blockchain applications developed by Communities for Communities we can already find. 
The Cryptourbanomics method aligns with Albert et al. (2000) [14] thesis and affirms blockchains are complex systems, not because of their ecology, but because of their evolutionary nature. In complex systems, macro-evolutionary events can be decoupled from micro-evolutionary ones to better understand complexity. Margalef found that complex systems shared a series of characteristics when exposed to perturbations/instability, which is called a universal architecture:

(1) existence of small worlds: high compartmentation between highly connected nodes and less connected ones. This leads to fragility before the elimination of highly connected nodes.

(2) Robustness regarding the disappearance of random nodes: the minimum of connections required to connect two nodes in the network is very low, very similar to the required by a random network, and this what makes complex systems robust (in reality complex systems - or small worlds—are in the middle ground of simple systems - totally organised regular networks—and totally random networks). Like all complex systems, communication networks display a surprising degree of robustness against loss of random nodes. This is attributed to the redundant wiring of their functional web defined by the system's components. However, as proven by Albert et al. [14] this is not shared by all communication networks, only exponential networks are robust in that regard, such as the World-Wide-Web, the early Internet, social networks, cellular automatons, etc. You might wonder why did we specify the "early" Internet and not the Internet alone. The Internet has changed much since 1992 and nowadays it would classify as a scale-free network and not as an exponential network because its degree of centralisation has increased substantially. In other words, decentralised networks such as blockchains are exponential and therefore robust against loss of random nodes whereas more centralised networks are not.

(3) self-similarity: very different complex systems will behave exactly the same when close to critical transition points. Therefore, the common feature of this self-similar behaviour will be the presence of scaling laws. Given the frequency distribution N(s) of some quantity (s), (number of species, size, lifetime, etc.), it is said that follows a power law if $\mathrm{N}(\mathrm{s})=\mathrm{Cs}^{-}$.

Let us assume that $\mathrm{s}$ stands for size, $\mathrm{C}$ is a constant and ${ }^{*}>0$ is a given exponent, often called the critical exponent. These laws are characteristic of fractal objects because they are only functions displaying invariance under scale change. If we look at a larger or smaller scale, if we take $\mathrm{s}^{\prime}={ }^{*} \mathrm{~s}$, it is not difficult to see that $\mathrm{N}\left(\mathrm{s}^{\prime}\right)=\mathrm{C}^{\prime}(\mathrm{s})$ or, in other words, a change of scale does not modify the basic statistical behaviour.

As mentioned in the previous section on Strategies and Transactions (Txs), blockchain Txs behave as cellular automatons and therefore have an infinite evolution over time and space. Moreover, as complex systems, blockchains will obey to self-similarity and scaling laws. Therefore, this infinite evolution of blockchains over space and time occurs within self-contained similar structures, that is Txs, blocks and the chain itself. Fractality, or the capacity to change scale maintaining similar properties across scales, involves a transition to a different state (scale) and this is described by "an order parameter", which is zero at the disordered or genesis phase and positive otherwise. Therefore, fractal systems can be of two types or be of both types:

- fractals in space, have features that look the same when there is a change in scale: "self-similar" patterns that occur at many levels.

- fractals in time, fluctuations of a given quantity can appear the same when observed at different temporal resolutions.

Infinite evolution over space and time means blockchains are fractals in space and time. If fractal structures and self-similar fluctuations are common in all complex systems, is perhaps because some universal dynamical processes are at work? The answer is yes. The most accepted scenario was proposed in 1987 known as self-organized criticality (SOC) or more commonly known as the Sand Pile model. Self-organized criticality is easily stated 
as follows: large, far from equilibrium, complex systems, formed by many interacting parts, spontaneously evolve towards the critical point following a fractal pattern. Margalef's disciples applied the SOC principles in ecosystems in 1999 [15]. Models of SOC systems are very simple and typically parameter-independent. Despite their simplicity (and because of their universality), they can be used to model complex systems. Complex system modelling tells us that, precisely, SOC occurs when complex systems reach the critical point because they seek equilibrium, even in critical situations. Reaching the critical point creates entropy within the system and complex systems achieve stability at the energetic cost of reducing entropy and increasing order. This energetic cost is called Cybernetics since it behaves as a cybernetic system. Cybernetics is the energetic cost of a Cybernetic system achieving equilibrium. A high Cybernetics cost will turn a system into equilibrium. Blockchains, like all complex systems, tend to an equilibrium, thus there are energetic costs of reducing entropy and increasing order to keep the system stable under critical and non-critical situations. These energetic costs are the cost of running consensus algorithms to deal with corrupt nodes, attacks and external factors attempting to cause disruption such as DDoS threats, Sybil menaces, etc. Thus, lacked from ecology and nature laws, blockchains were born with an anti-disruption system to stay in equilibrium. Therefore, we can affirm that blockchains cause external disruption but cannot be internally disrupted.

In blockchains no entropy can exist, no opposite species, no disruption. However, small degrees of diversity can exist given that they do not evolve towards disruption. This is why blockchains have to have an inherent cybernetic system: the consensus algorithms (PoW, PoS, PoA) and their associated cryptocurrencies to reward the mining efforts of running consensus algorithms to keep diversity in check. Indeed, there would be disruption in blockchains (for instance good-will behaviour vs corrupt mentality caused by opposite species e.g., white hats vs attackers, and this would cause threats e.g., DDoS attack, Sybil menace, etc.) if it would not be for consensus algorithms. The most relevant consensus algorithms are Proof-of-Work (PoW), Proof-of-Stake (PoS), Proof-of-Authority (PoA). PoW (It is worth highlighting the relevance of the PoW, first introduced by Satoshi Nakamoto in Bitcoin, as it presents a more viable alternative to solve the years-old Byzantine Generals' Problem than other consensus algorithms. In the traditional description of the problem, generals, whose armies are spread around a target city, need to reach consensus on a time to attack. To achieve this, they can only rely on unsecured communication channels, whereby, for instance, a lack of acknowledgement can either be caused by a failure to deliver a message, by the death of a general or by a failure to deliver the acknowledgement. This problem is commonly known as the Byzantine Generals' Problem, and mitigation strategies as Byzantine Fault Tolerance. Byzantine Generals' Problem is so complex that Byzantine complexity has come to refer to any overly complex system. The big breakthrough when Bitcoin was invented, was the use of Proof-of-Work as a probabilistic solution to the Byzantine Generals Problem as described in depth by Satoshi Nakamoto in one of his emails (Available online: https:/ /www.mail-archive.com/cryptography@metzdowd.com/ msg09997.html (accessed on 22 February 2021). What PoW does is to use digital signatures in the Byzantine Fault Tolerance algorithm, which requires $2 / 3$ of nodes to be honest. The use of digital signatures reduces the need for hones nodes down to $51 \%$.) is the consensus algorithm that allows for the minimal diversity due to its increasing centralisation because of the need for specific mining requirement to participate in the network, which excludes non-professional miners. PoW is used in pseudonymous networks such as Bitcoin and Ethereum and anonymous ones like Monero. Another anonymous blockchain is Zcash, which uses zk-SNARK technology based on zero-knowledge-proofs, a ring signature used in anonymous networks. Older PoW networks get more exposed to a $51 \%$ attack because mining difficulty decreases over time. Lastly, PoW is an energy predator. For instance, it is said that Bitcoin consumes the same amount of energy as Nigeria as a country. PoS introduces more diversity. The consensus algorithm allows for anyone to participate as miner given that selective entry fee is paid. The PoS is criticized because it selects as validators participants with the highest economic stakes and this raises concerns as: 
How can a majority-based consensus system adequately protect and provide for minority interests, in particular where voting influence is weighted in proportion to the number of tokens held? PoS is used in pseudonymous and identity-based networks. Reputation is at stake. Because reputation is attached to identity, validators are incentivised to uphold the transaction process since they do not wish to have their identities attached to a negative reputation. Is more energy sustainable than PoW. No implementations yet although Ethereum, at the time of writing is about to switch from PoW to PoS. Lastly, PoA. It allows for maximum diversity since mining is allowed to trusted nodes, being possible to have a large network of trusted nodes. It is used in identity-based blockchains and it is, therefore, most suitable for government-led/participated projects. Validation is restricted to trusted nodes, which means that mining is reduced to the minimum since network security it is guaranteed with participants' own identity, therefore not requiring expensive computational operations. PoA is more robust than PoS and safer than PoW because it only allows non-consecutive block approval from anyone validator, meaning that the risk of a serious network attack is minimised. Moreover, it is as energy sustainable as PoS.

If the different types of consensus algorithms are the cybernetic mechanisms that blockchains use to manage entropy caused by $\mathrm{Tx}$, and blockchain networks range from anonymous to identity-based, this means that entropy can be known and unknown. When entropy is unknown, Tx has to be signed without unveiling parties' identities. In cryptography, a zero-knowledge proof (or zero-knowledge protocol) is a method by which one party (the prover) can prove to another party (the verifier) that she knows a value $x$, without conveying any information apart from the fact that she knows the value x. Another way of understanding this is: zero-knowledge proofs require interaction between the individuals (or their computer systems) to prove their knowledge on one side and validating the proof on the other.

As a summary of what has been described so far, blockchains are complex systems of evolutionary type due to their cellular automaton nature. Blockchains cause external entropy and thus disruption but they cannot hold internal entropy, hence the existence of consensus algorithms, to pay the cybernetic costs of avoiding internal disruption. But, since physical environments, such as cities, are complex systems as well (of ecological type, as we will see in a moment), how disruption caused by a blockchain project in such civil space will affect that environment's own diversity and disruption? Will it have an incremental disruptive effect? Will it counterbalance disruption and even it out to zero? Urban environments are complex systems of ecological nature and, like all complex systems, are open systems and thus generate entropy due to their continuous exchange with the outside. In urban systems, their organic matter follows the second principle of thermodynamics by which it uses the energy from outside to degrade itself, entering this way into an entropic process that always tends to a critical point. On the other hand, species follow Boltzmann's informational laws and the energy they consume from the outside is to "grade" themselves, following an entropic process that transforms entropy into information and complexity. Hence the high similarity between Boltzmann's, 1872, formulae of entropy (left) and the calculus of information (right):

$$
\mathrm{S}=\mathrm{K} \cdot \log \mathrm{W} \quad \mathrm{S}=\mathrm{K} \ln \ln ^{\prime} \Omega
$$

Later, in 1948, Shannon develops the Theory of Information (Its unit is "information bits", where: $\mathrm{Pi}$ is the probability of occurrence that the members of a Community with a certain profile will interact with members with a different profile. It is about knowing the number of portrayers of information with capacity for contact, in quantity and variety in a given space. Therefore, $\mathrm{H}$ is an indirect measure of the organization of the complex system), by which the mean of a complex system's information can be calculated:

$$
H=-\sum_{i=1}^{n} p_{i} \log _{2} p_{i}
$$


Both entropy and information are probabilistic concepts which tend to the most likely status, and therefore, increase seeking the critical point. In species, entropy tends to chaos, becoming informational complexity. Certain informational complexity has no interest and it is therefore called "noise". It is a form of non-organised information which is noncognitive. On the other hand, organised information generates cognitive complexity, which is the basis of species' evolution. Therefore, in final terms, information mean $(\mathrm{H})$ will be the information generated when broadcaster and receiver exchange organised meaningful messages. Diversity is somewhere between disruption and equilibrium. Diversity has degrees. Higher degrees mean more entropy, less order and therefore more information generated. Diversity and disruption will appear when cybernetic costs are not fully paid and therefore there is no equilibrium. As ecological complex systems do not have natural mechanisms to control entropy, they will naturally tend to the critical point and chaos, seeking equilibrium. Policies are superimposed legacy instruments to break the tendency of natural systems to the critical point but still allow for diversity (something that a regulation would not allow to do). When introducing blockchain technology, the legacy system will be either removed (disintermediation) or put into question (coexisting systems). And this is what will disrupt the legacy system but blockchains are not disruptive per se. Actually, the technology will let the community control their own degree of diversity in the newly organised system while keeping disruption under control thanks to consensus algorithms. Importantly, as Margalef colleagues said "ecosystems do not dance on top of a nail" (see Figure 3), and blockchains will not either when used in physical environments! This meaning that blockchain-based projects taking place in the physical environment will be inevitably territorialised.

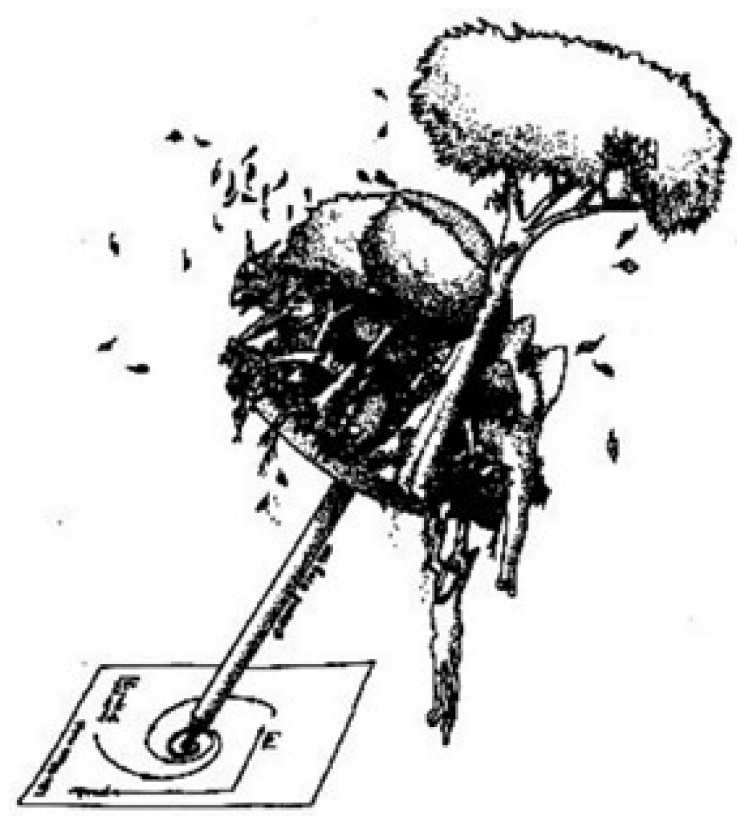

Figure 3. Margalef's colleague, RV Solé, drew this sketch to illustrate what Margalef said endlessly: "ecosystems do not dance on top of a nail!", and nor blockchains do. Source: https: / www.estudiomc. es/documentos/margalef-y-el-espacio.pdf (accessed on 22 February 2021).

The territorialisation of blockchain projects occurs through tokenisation since the connection between on-chain participants and their off-chain location is made with where and when tokens are transacted. We will continue using the use case on the Right to Work and its sub-clause on ending youth unemployment to visualise this connection. Peers (employer and employee candidate) previously connected via the Public Agora Dashboard and having their pseudonymous identity on the Cryptourbanomics blockchain will receive tokens for their time on-chain. This is because the Cryptourbanomics blockchain is designed as a PoA in which all users are mining nodes. Therefore, blockchain maintenance 
is made with your on-chain presence and this is rewarded with Cryptourbanomics own currency, the Ars token, or local cryptocurrency. Moreover, peers budget will grow every time an employment agreement is implemented. For instance, let us say that an agreement consists of a gardening company hiring an unemployed farmer to transform the patio of local public school into an orchard, to teach kids on organic food and harvests to be used to celebrate classmates' birthday parties instead of sugary cakes. All this good work done by the farmer will be paid in Ars, which the farmer will be able to use to pay for services or products in another facility also participating in the project. It is this local virtual-physical flow what will create blockchain entropy, to finally disrupt the local economy and deliver on the promise of ending youth unemployment in the targeted area. Elaborating on this idea, Sun et al. [16] sustain that blockchain technology can completely change how resources are shared within communities since it improves accessibility and availability of physical systems. The Cryptourbanomics method uses the Ars local cryptocurrency as territorialisation mechanism to establish the actual connection between the on-chain and off-chain elements, population and their environment, showcasing blockchain's socially embedded features and proving blockchain's disruptive capabilities.

Now the question is, why the Cryptourbanomics method pairs Tokens and Policies sustaining they are both disruptive instruments? And, according to Figure 1, why are Tokens going to empower users in designing the cause of their own Policies? As mentioned at the very beginning of this section, Policies are the most disruptive tool within legacy codes because they still allow for diversity. Tokens are an instrument to store value that can be exchanged either for a service (utility token) or as a promise to return some value in the future (security token). Therefore, tokens are tools allowing for the management of an environment, a high-level mechanism to run Policies empowering users in selforganising their own diversity levels while keeping disruption in check thanks to consensus algorithms, which are intrinsic to blockchains and therefore present in any Tx. Moreover, as we will see later, tokens are tools that are halfway through a decentralised autonomous organisation, the most sophisticated blockchain tool.

\section{Distributed Planning Relies on Crowd Sales for a Granular Implementation of Disruptive Policies: The Ars Community Market as an Example}

The second pillar of Urban Sustainability is Economy. In this section, it will be presented how the Cryptourbanomics Method helps deliver on the economic sustainability of communities by relying on blockchain's distributed capabilities. For that, we will leverage Ildefons Cerda's theories of urbanisation, the first system for equalitarian distribution of assets in the city.

It might be already clear, from the two sections already studied, that the Cryptourbanomics method builds on the previous component of the method. This is because both, blockchain code and traditional codes do. Therefore, Disruptive Policies and their tools take on Disintermediated Strategies and build on their instruments. This cumulative effect will become more evident in this third stage of the method, where Planning builds on Policies. So far, we have seen how blockchains can be Disintermediated thanks to Txs cellular automata behaviour [10]). Regarding Disruption, blockchains can cause it because they are complex systems [14]. And, concerning Distribution, how do blockchains behave? Like state machines. According to Saito and Yamada blockchain infrastructure is considered a state machine since it consists of a network to distribute and manage state transitions. A general definition of a state machine is that of a technology that manages and distributes transitions towards a physical stage. A vending machine is a good example of a state machine, it allows users to transit from a physical state 0 (e.g., without coffee) to a physical state 1 (e.g., with coffee in their hands): when you insert the coin, you will move from state 0 to state 1 . Further, on state machines, these can be infinite or finite. A computer is a finite state machine since it can only be on or off, whereas a vending machine is non-finite since it can be off or on but, within the on state, it gives you a wide range of physical outcomes/products, meaning it has multiple on states. It is important to highlight that whether a state machine is finite or infinite, the change of state involves physical 
elements (the vending machine will give you a physical product, the computer will heat up when on, etc.). The same authors Saito and Yamada [17] define blockchain technology as an infinite state machine that uses consensus methods to agree on each new state of the distributed peer-to-peer network, that is, the longest chain will decide on the new state of the blockchain machine.

Accordingly, applying the Cryptourbanomics method logic we can say that when blockchain technology is used to Disrupt Policies, their physical Distribution will behave like a state machine. To understand this correlation let us review one of the earliest and few examples of change of state in urban policies, in other words, a distributed physical implementation of Policies. In late sXIX, Ildefons Cerdà pioneered the urban planning we know today, which is the legacy code used to physically implement urban Policies. Hence, Cerdà is considered the father of urban planning. Urban planning, like blockchains, is a state machine mechanism since it allows for multiple physical outcomes from a given set of initial planning parameters. It also has to be noted that Cerdà, in his early implementations of urban policies used very disruptive Policies, introducing novel concepts close to what today we call "right to the city". Here is an example: "The city extension will be our common heritage, owned by each of its inhabitants. All citizens have the right to sunlight, fresh air, sky views, nature smelling breeze, unburdened traffic circulation, and open views to a pleasant landscape; in other words, having equal rights to the public realm compares to equal rights to life. [18]". Another similarity between the physical distribution through planning proposed by Cerdà and blockchain distributed nature is that Cerdà designed his planning principles with an embedded economic model, which reminds of blockchain mining fees. Cerdà limited urban blocks construction down to two thirds, leaving the remaining third unconstructed and therefore unprofitable as means to provide for public space. This is very clear in one of his quotes in which he addresses developers: "Do you want an extra park? The extension plan is prepared for that, just substitute a block and include a garden instead (... ). But include these at your own expense, thus this benefit will be all yours. Money can buy you extra wellness and luxury hygiene but do not request the disadvantaged citizen to help you buy these, since this would cause unfair inequality, and would give you a preference that would be attempting equal rights to the city [18]".

Cerdà created an Urban Planning theory $[19,20]$ to Distribute his Disruptive Policies. He conceived an infinite scalable granular matrix that could be replicated in any city. And because he was very concerned about equality between all citizens, his matrix was a distribution mechanism of all city ingredients, and is, therefore, resulted in a complex and diverse city model, the so-called "compact city". This is why he is also considered to be the father of the compact city model. Cerdà's compact city model is infinitely scalable because it is granular, we can therefore say it is fractal (taking elements of Disruptive Policies, thus building on the previous stage of the Cryptourbanomics method). Fractality meant that not only city districts had complexity and mixture, so had the blocks. He brought distribution and complexity at the lowest possible level, the block unit. Thus, in Barcelona's Eixample, his opera maxima, we cannot find residential blocks only since these include a collection of various functions: all blocks had a proportion of public space, a commercial piece, labour units (ateliers), and even some small public facilities such as public administration sites. As a second characteristic, Cerdà's compact city model is infinitely scalable because it is granular, thus multi-scale (again, taking from the previous level). He proposed micro and macro-scalability systems and he reserved those for the reinforcement of those public assets he considered of vital importance, open spaces. Accordingly, he proposed the one-third micro-public space policy in all blocks and two macro-parks at both east and west extremes of the city. These were his arguments for having reinforced the macro-scale: "A large city, with a mostly working population, needs big leisure spaces ( ... ); a large extension of open-spaces nicely covered with grasp and shadowed by forest, perfumed by balsamic plants and bushes, crossed by small rivers, accented by ponds; all this being of very easy maintenance since this will be all-natural, almost left at its own, only cared by good citizens' behaviour, which does not understand of social classes but civic rules [18]". 
As the third and last characteristic, we find that Cerdà's compact city model is infinitely scalable (see Figure 4) because it is granular, and this granularity allows for polycentrism. His equalitarian vision of the city translated into a city plan with multiple centres (multi-centrality), organised around a sum of $5 \times 5$ blocks (see Figure 5). This generated districts which, in fact, where matrix subdivisions where he proposed a square at the centre accompanied by several public facilities, being the main one a public market, but also schools, hospitals, etc. As Cerdà's legacy, today we still have 10 public sheltered markets in Barcelona, meaning that his original matrix had 10 mini-districts, gathering an average of 25 blocks.

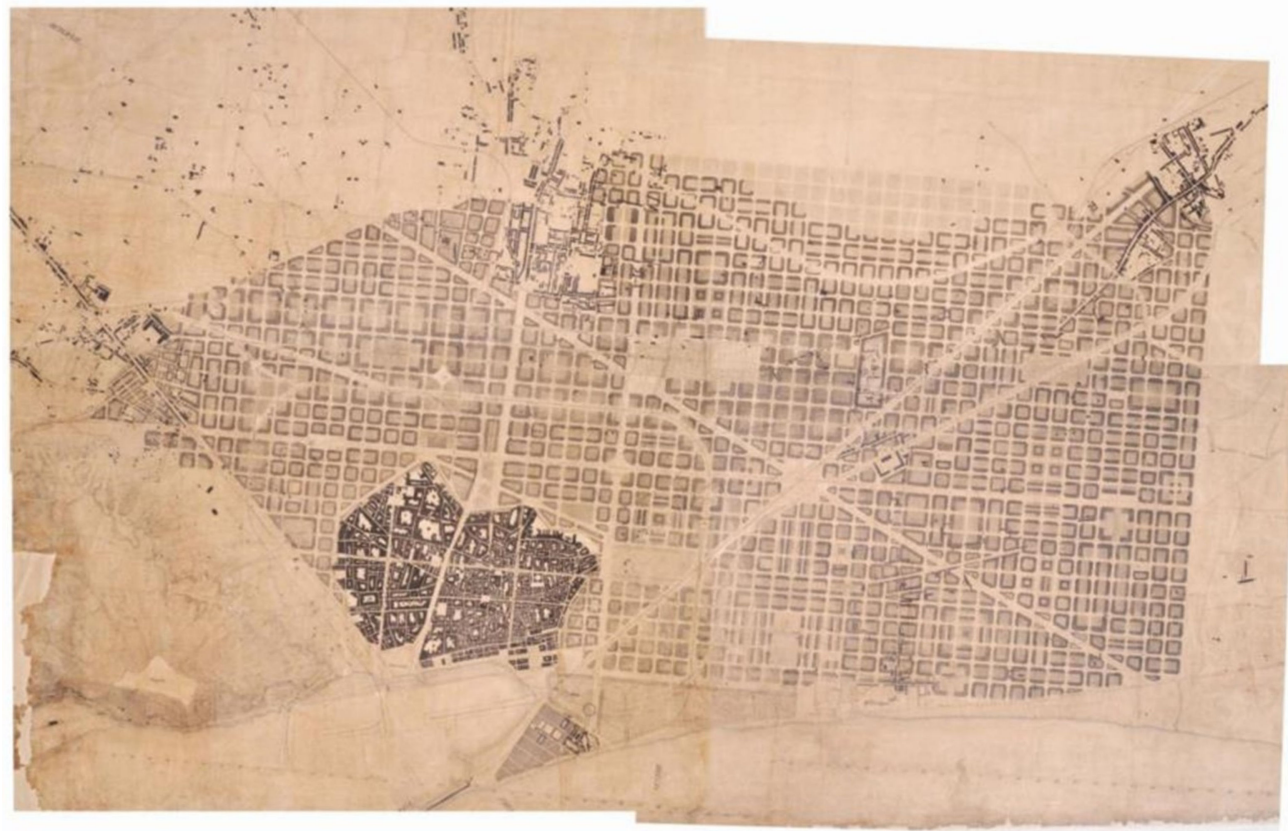

Figure 4. Cerdà's original map for Barcelona's Eixample, one of the first examples of distributed communities. Source: http:/ / www.anycerda.org/web / arxiu-cerda (accessed on 22 February 2021).

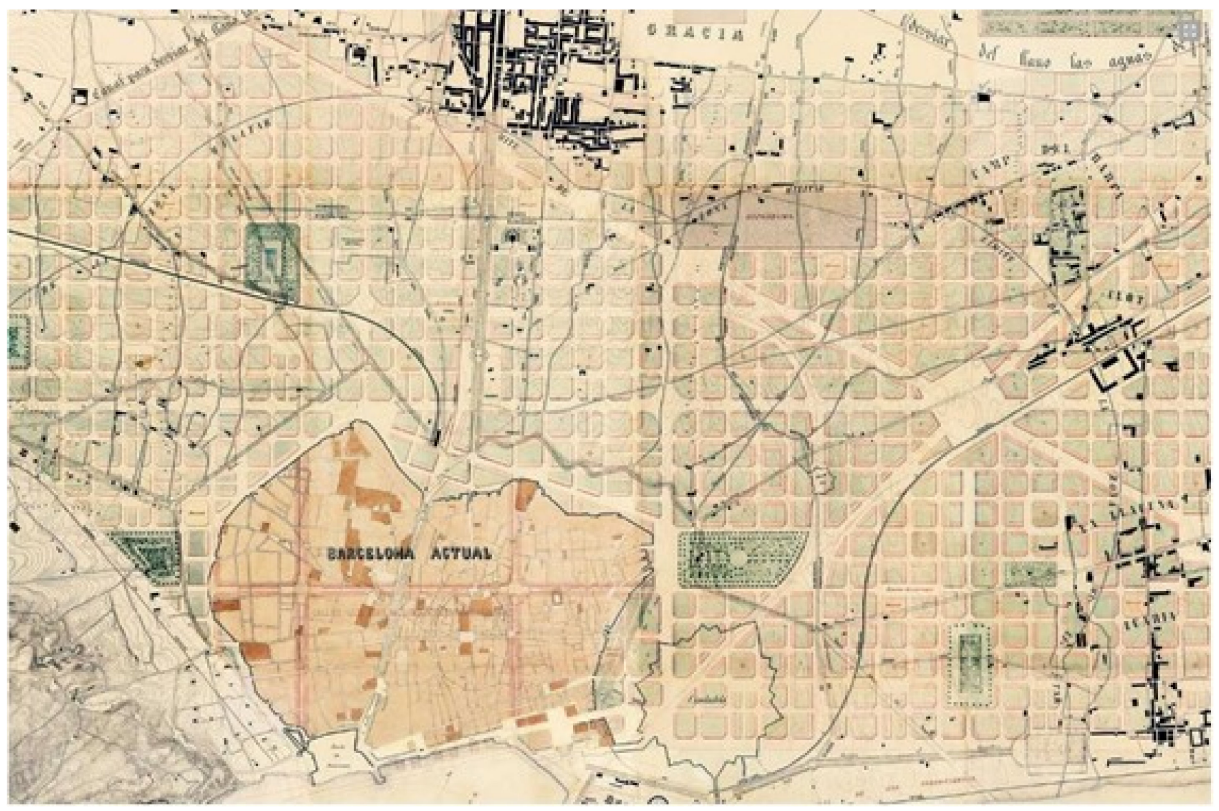

Figure 5. Eixample's central districts. His distribution principles were based on an equalitarian Right to the City. Source: http://www.anycerda.org/web/noticies/Comenca-una-altra-de-les-gransexposicions-de-1-Any-Cerda (accessed on 22 February 2021). 
Blockchains are following different pathways to becoming even more distributed or, if you want, not to limit their distribution potential. As we will see in this paragraph, blockchains enhanced distribution mechanisms have a high resemblance with Cerdà's distribution model and this is due to both being state machines. Blockchains were born with a granular but flat distribution, this is a homogenous network of nodes all keeping the same blockchain record. This granular and flat distribution, although positive, poses scalability problems. As state machines, scalability solutions currently being brought into the blockchain leverage on granularity in a similar way as Cerdà's compact city model: Cerdà's fractality is blockchain "sharding", Cerdà's multi-scalability expresses in blockchains as "side chains", and Cerdà's polycentrism has parallelism in blockchains as "payment channels". Sharding is a very old concept used in centralized database design. A database shard is a horizontal partition of data in a database. Each individual partition is referred to as a shard or database shard. Each shard is held on a separate database server instance, to spread the load. It, therefore, means breaking up your database into multiple separate databases which do not share any common data at the same horizontal level but that is contained in upper levels. Blockchains such as Ethereum are looking at sharding as a potential solution to grow their distributed ledger by splitting into the different nodes. As for the correlation between physical and virtual Distribution Blockchain Policies implemented through sharding would mostly express as a fractal structure. A second solution to blockchain scalability problems we find sidechains. A sidechain is a blockchain that runs in parallel to the main blockchain allowing for decentralized transactions between the two chains. You can move your native ledger to the sidechain and then back to the main chain. Sidechains are separate independent blockchains with their own consensus mechanisms, mining/minting algorithms and transaction formats. That is why each side chain can have its own cryptocurrency. Blockchain Policies implemented through side chains would manifest as a multiscale structure. Lastly, we find Payment Channels, like Bitcoin's Lightning Network and Ethereum's Raiden. In very simple terms, payment channels leverage dropping the Tx signature from a UTXO (unspent transaction output, which is the status of a Tx before it is spent). As all Tx are initiated with a signature a replacement mechanism has been found and Payment channels use the solving of a mathematical problem instead. This signature, instead of going to the blockchain as part of the Tx, is gathered in a Merkle tree, releasing block space. This also means that not all transactions will have to go through the blockchain but only the Tx that will open and close the channel. Payment channels are ideal for regular Tx between two accounts and will require multi-signature from both accounts or the exchange of a specific secret. Even, to strengthen security, these two can be combined. Moreover, Tx have to be bi-directional between accounts and be "hash locked transactions" meaning that who knows the value of the hash can spend. The ultimate sophistication of this is that the multiloop payment channels which allow for atomic payments in a coordinated way. Blockchain payment channels would physically manifest as polycentric structures.

Scalable granular Distribution, either through sharding, side chains or payment channels, is key to blockchain resilience since it ensures no single point of failure at present and in future stages of network growth. Same for resilience in cities, fractality, multiscalability and polycentrism will ensure continuous operation in cities even when new developments are added. And resilience is not only virtual or physical, as a result of the granular distribution of elements being part of the network (e.g., nodes in a blockchain or power stations in a city), it will also have social, economic and environmental resilient benefits. For example, the more distributed economic activity is, the better options are given to entrepreneurs and businesses to succeed. This will have a positive impact on society, improving economic and social resilience as well. There is an interesting debate on whether the best physical expression of granular and scalable distributed urban systems are more like Paris and less like Brasilia. In the author's opinion, the ideal layout is somewhere in between, like in Cerdà's Barcelona. Over planned cities such as Brasilia do not scale well as it is difficult to include fractality, multi-scalability and polycentrism in their locked-in 
masterplan designs. On the other hand, organically planned cities like Paris or London do not scale well either since the lack of pattern makes it difficult to include fractality, multi-scalability and polycentrism consistently and harmonically. The growth of cities tends to speed up even as population increases because of network effects. The same is true for blockchain networks; the larger and more robust the community, the more valuable the crypto network. The way you architect a successful city and the way you architect a successful network are very similar. In summary, both blockchains and urban planning tools are state machines of infinite type. Their infinite outcomes translate into a granular scalable effect. This allows for the direct implementation of blockchain distribution tools in physical support, resulting in the territorialisation of blockchain tools and therefore a fine-grain scalable implementation of Disruptive Polices.

Back to our use case on the Right to Work and ending youth unemployment to illustrate what has been described. Once a specific cause has been selected within a cause, ending youth unemployment within the Right to Work cause in our example, distributed physical implementation starts. Since causes and their sub-clauses are usually felt unevenlyor, what it is the same, are unequally distributed-across the city (e.g., youth unemployment might have more presence in poor districts), this will reinforce the need for a fine and very granular distribution of their physical implementation. It will be actually the same participants in the project who will be better placed to tackle the granular distribution of their challenges. For instance, in our use case, the farmer who already got a job at the school to grow veggies and fruits on school patios might see an opportunity for a cook to participate in the elaboration of healthy meals for students using these harvests and, accordingly, he will suggest to the canteen director to sign up in the Public Agora dashboard and post this opportunity. Hopefully, the right candidate will sign up too and the school will now have an employed cook joining in and running the canteen using orchard's surpluses and charging meals in Ars. This is how an Ars Community Market is formed (a market focused on jobs in this example) and how the use of the Ars cryptocurrency can grow exponentially.

\section{People's-Delegated Regulations Can Be Achieved with Governance Ran as a Decentralised Organisation: The Parliamentarian Proof of Reductio ad Impossible as an Example}

The third pillar of Urban Sustainability is Society. In this section, it will be presented how the Cryptourbanomics Method helps deliver on social sustainability by relying on blockchain's decentralisation capabilities. To that end, we will capitalise on Ramon Llull's works on logical decision making, the earliest example of a bottom-up decentralised governance system.

As mentioned in the introduction, blockchain is the technology that can provide answers to causes and challenges unheard or unaddressed by the System. The set of blockchain tools we have seen in previous sections enable the implementation of more citizen-centred legacy codes, that is Strategies, Policies and Planning. This section showcases the benefits of pairing the most sophisticated blockchain tool, Decentralised Autonomous Organisations (DAOs) with the most complex legacy code, Regulations so that challenges can be Decentralised and governed by citizens. A DAO is a fully automated organisation that exists only in code but performs all actions a traditional or legacy organisation would do such as contracting providers, delivering projects and proposals, paying salaries, taking business decisions, etc. The main difference is that, in a DAO, organisation participants are represented via their accounts and they can delegate their decision-making tasks to other participants making use of a blockchain protocol called Liquid Democracy. Another important characteristic of DAOs is their democratic modus operandi, which implies all decisions are voted and have to be in consensus. DAOs can be set up by anyone willing to tackle a cause remaining unsolved or not properly addressed by the system. Therefore, DAOs are a promising, people-centred, alternative to traditional forms of governance. Today's Community-based governance in cities is only possible through public participation and consultation and cities somehow went backwards on that: in the medieval era, one 
of the thinkers of that time, Ramon Llull (Mallorca, c. 1232-1315 or 1316), put forward an innovative Jury operated through wisdom and delegation. This allowed for more informed decisions than the ones we are making today with current public participation mechanisms. In other words, cities were possibly more decentralised in the medieval era than they are now. Blockchains use these basic decentralisation principles that, as with Llull, rely on delegation. Delegation requires the use of notational combinatory logics as the instrument empowering reasoning in the decision making and, thus enabling delegation. Moreover, the advantages of notational combinatory logics are that delegation can be based on reasoning affinity and not a mere geographical proximity.

The blockchain tools for developing decentralised governance are Blockchain Congress and Liquid Democracy. The latter is a powerful delegation instrument which expresses in two forms, House of Representatives and the Executive Branch, with incremental use of delegated powers respectively. Blockchain Liquid Democracy can help cities become more decentralised and city planners and policymakers should plan for the introduction of those instruments to build a truly participatory democratic society. In previous sections, we learned that the Disruptive behaviour of blockchains is due to their complex system nature [12] and that their Distributed nature is because blockchains are infinite state machines [17]. When it comes to Decentralisation, we will learn that the lack of a central authority and its replacement by a blockchain-based democratic organisation is possible because of their embedded notational combinatory logic [21]. Combinatory logic is a notation to eliminate the need for quantified variables in mathematical logic. It is based on combinators, a higher-order function that uses only function applications and earlier defined combinators to elaborate a result from its arguments. It is no surprise that the paternity of combinatory logic is given to Lull, along with his medieval implementations of decentralisation and delegated governance in cities. Llull designed a reasoning system he called the Ars, as an alternative to the imposition of sacred texts, aimed at achieving better evangelization results amongst non-Christian. He evolved his Ars to the point of being a pioneering logic for decentralised decision-making, in what he called the Ars Combinatoria. In this section, we will learn the shared characteristics between Llull's and blockchains notational combinatory logic.

Llull created an Alphabet as the basis of the Ars. In his Alphabet, Llull analysed and abstracted the common elements of any religion, being monotheism, certain common qualities of this one God, Aristotle's as a common philosophical framework, and the use of Greek science to understand the world, which taught about the earth at the centre of a universe with seven planets rotating around it, and that this earth of ours was composed of four elements, fire, earth, air and water. He organised all these findings in the method of the Ars in which he combined both theological and scientific components to produce arguments that could not be rejected by the targeted groups, Muslims and Jews. Llull realized that people better-understood figures than text. He, therefore, worked out the Ars so that its logic could be solely presented with graphics [22] This resulted in the Ars Combinatoria. Llull's Ars Combinatoria essentially consists of 4 evolutionary figures and it is based on his Alphabet of 9 letters in which each letter had 6 possible meanings that could be combined to form different notations and arguments to be solved logically. To combine the different meanings and solve notations and arguments he created 4 figures, Prima, Seconda, Tertia and Quarta Figura, as shown in Figures 5 and 6 (for a complete description and visualisation of Llull's Figures and his Alphabet, please visit Stanford Encyclopaedia of Philosophy, Available Online: https://plato.stanford.edu/entries/llull/ (accessed on 22 February 2021). Moreover, his logic allowed to create new insights by formulating and solving questions within the figures. Prima Figura, it is said is the earliest example of permutations [23] an important contribution not only to today's computer science but to blockchain technology. Observing the Prima Figura, we can identify an " $\mathrm{A}$ " at the centre, this tells us that it has its origins in a previous Figure, named " $A$ ", in which he initiated explorations on permutations. A permutation consists of a given set of $\mathrm{n}$ elements, all 
different, the number of possible combinations, in any order, is given by their factorial, which is represented as $n$ ! and is calculated as $1 \times 2 \times 3 \ldots \times n$ ).
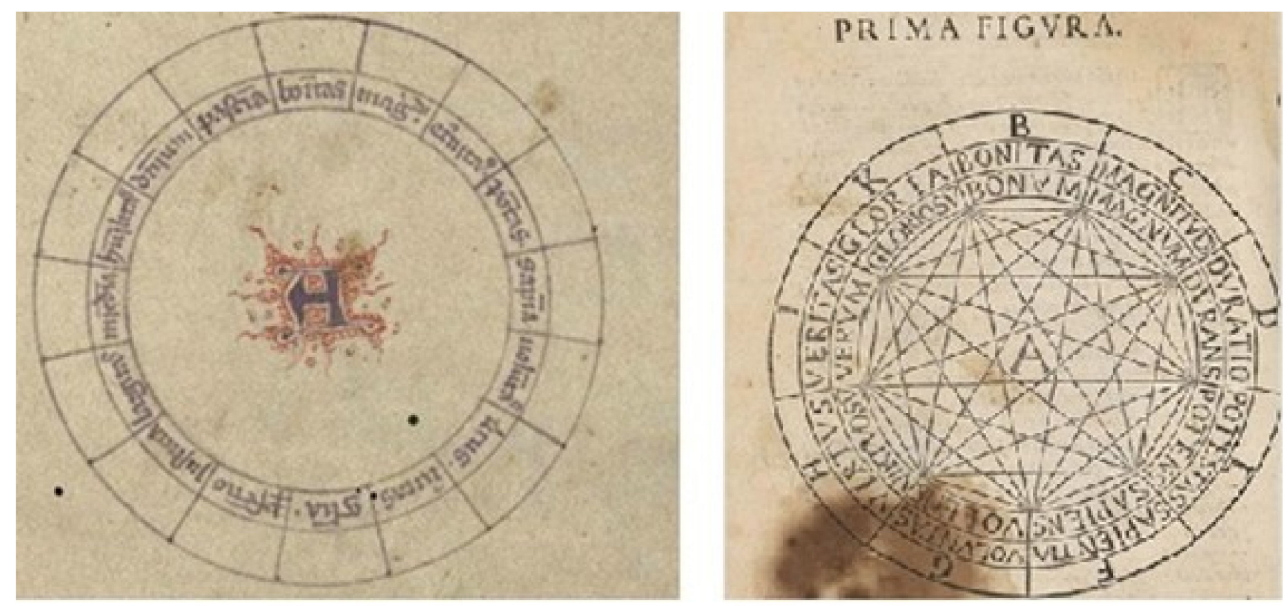

Figure 6. Figure A (left) and Prima Figura (right). Llull's decision-making method is considered to be the first logic machine. Source: https://plato.stanford.edu/entries/llull/ (accessed on 22 February 2021).

Blockchains use permutations since all transactions are hashed. A hash is a cryptographic function to convert a variable number of data into a fix new term based on a system of permutations. A hash cannot be unfolded or decrypted (unless all permutations are essayed which, usually, is computationally not doable) therefore original encrypted data remains safe. Back to Prima Figura, we can observe it is formed by an outer circle containing the 9 letters of the Alphabet and two inner circles with the First Meaning of the Alphabet in two forms, like adjectives and nouns. Lines in the centre show permutations of letters and their Meanings: 72 possible combinations such as "goodness is great" or, in the opposite direction, "greatness is good". Seconda Figura has two predecessors, Figure S, which is the oldest example of combinatorics [22] and Figure T, an inspiration to consensus algorithms [24]. In Figure S, Llull wants to represent the Soul since it is the essence of any Specie. Llull considered the Soul was formed of three elements, Memory, Intellect and Will. Llull was interested in representing all possible combinations of these three elements, thus resulting in twelve different kinds of species $(b, c, d, e, f, g, m, n, p, q, r, s)$ placed in the edges formed by the rotation of the three squares at the centre of Figure S. Excluding the edge containing the Specie that one wants to study, the other edges of the squares point at an inner circle with attributes of the Second Meaning of the Alphabet. The squares also point at two outer circles which show Prima Figura's adjectives and nouns. Using these three layers, Llull defined the Soul of the different Species and created different types of Beings (e.g., Intellect that understands, intellect that fails to understand, intellect that doubts; a memory that remembers, a memory that fails to remember, a memory that supposes; will that loves, will that hates, will that believes). Note the use of "opposites" to reflect the behavioural reality of Beings, sometimes contradictory. In Figure T each of the edges of the triangles connects the terms of the Second Meaning (Figure S) with the different Beings included in the same-colour circle sections and with terms of the First Meaning Alphabet. This correlation allows to qualify the different Beings through relationships that can be established between them (e.g., Intellect that understands is different from an intellect that fails to understand, and is concordance with an intellect that doubts; a memory that remembers is contrary to memory that fails to remember, and it is different from a memory that supposes; will that loves is contrary to a will that hates and equal to a will that believes).

In the first period of the Ars, when Llull was developing preparatory figures such as $\mathrm{S}$ and $\mathrm{T}$ (see Figure 7), he created notations or proofs by pairwise comparison of concepts, what he called Ars Demonstrativa. This is why Figures $\mathrm{S}$ and $\mathrm{T}$ include opposite concepts 
(not the Seconda Figura), for instance "goodness" (1st meaning) understood as a synonym of "majority" (2nd meaning) and therefore the opposite of "minority" (2nd meaning). Hence, following the Ars Demonstrativa, the same term can have opposite meanings since positive and negative hypothesis can be explored. Figures $S$ and $T$ positive and negative hypothesis (e.g., "goodness is a minority" and "goodness is not a majority") are proven by what Lull calls reductio ad impossible, which inspired today's consensus algorithms. In reductio ad impossible the concordance between "majority" and "minority" is clearly impossible therefore, the existence of "goodness" is proven by reductio ad impossible. Seconda Figura further adds to computer science with its primitive encryption rules [25] Seconda Figura allows us to build and analyse the tree of relationships between meanings and Species created by $\mathrm{S}$ and $\mathrm{T}$ and from those prove the meaningful ones making use of Ars Demonstrativa's proof of reductio ad impossible which will result in Beings and all its descriptive trace encrypted under a single letter (b, c, d, e, f, g, m, n, p, q, r, s). In the contemporary context of cryptography, Seconda Figura's relationship model and Ars Demonstrativa's rules remind us to Merkle trees and hash rules used in blockchains by which batches of valid transactions are hashed and included in blocks that will be further hashed and included in block's Merkle root. In blockchains, the longest chain is the only considered valid thus, additional to the hash function, consensus algorithms are needed to agree on the longest chain. Consensus algorithms implement a collection of rules to create a hash chain by calling the previous block hash and creating a new hash that also contains the hash of the previous block and so on.
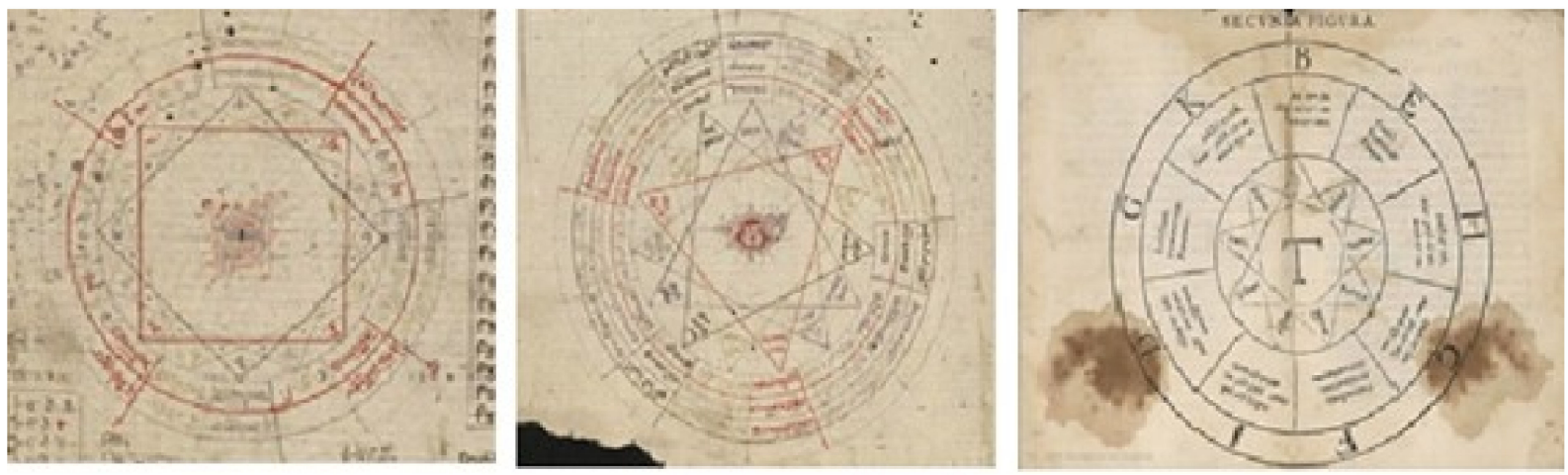

Figure 7. Figure S (left), Figure T (centre), and Seconda Figura (right). Proving capabilities of Llull's method provide users with a self-governance tool. Source: https://plato.stanford.edu/entries/1lull/ (accessed on 22 February 2021).

The Tertia and Quarta Figura are formed similarly (see Figure 8). Unlike Prima and Seconda Figura, these two do not refer to the First and Second Meanings of the Alphabet but all six meanings. This means that letters included in these figures can have up to 6 different meanings therefore a pair in the Tertia Figura can have up to 36 different meanings whereas in the Quarta Figura a triplet formed through combinations of its three discs can have up to 216 different meanings. The development of these sequential rules initiated in the Tertia Figura has computer science logic and therefore can be understood as primitive software rules [26] Tertia Figura is a half matrix. This is because he made no distinction in the order of letters ( $\mathrm{BC}$ and $\mathrm{CB}$ were the same so that one of the pairs could be avoided), this made the other half of the matrix unnecessary. Moreover, this half matrix has no main diagonal since redundant pairs such a BB or CC were not allowed. If Tertia Figura advances combinatory logics with simplification, Quarta figura does so with complexity. Quarta Figura has three concentric circles, each of them drawn in an individualised piece of paper. By turning the three discs, different combinations are formed. With both binary (Tertia Figura) and ternary (Quarta Figura) combinations of the six different meanings of his alphabet, Llull wanted to represent all possible states of the human mind (taking humans as the Specie and the mind as human's Soul) when in a given reality (and thus becoming a different Being depending on the reality). This first "paper computer" was meant to represent how 
human beings functioned by mapping the different possibilities the human mind could think of to understand the world. Llull's ternary combinations have been referred to as the earliest "hardware" contribution to computer science [24] and therefore awarded him with the paternity of being the first 'paper computer' that, in addition to his "software" contributions on sequential rules, encryption, consensus mechanisms, combinatorics and permutations show Llull's undeniable relevance to computer science.
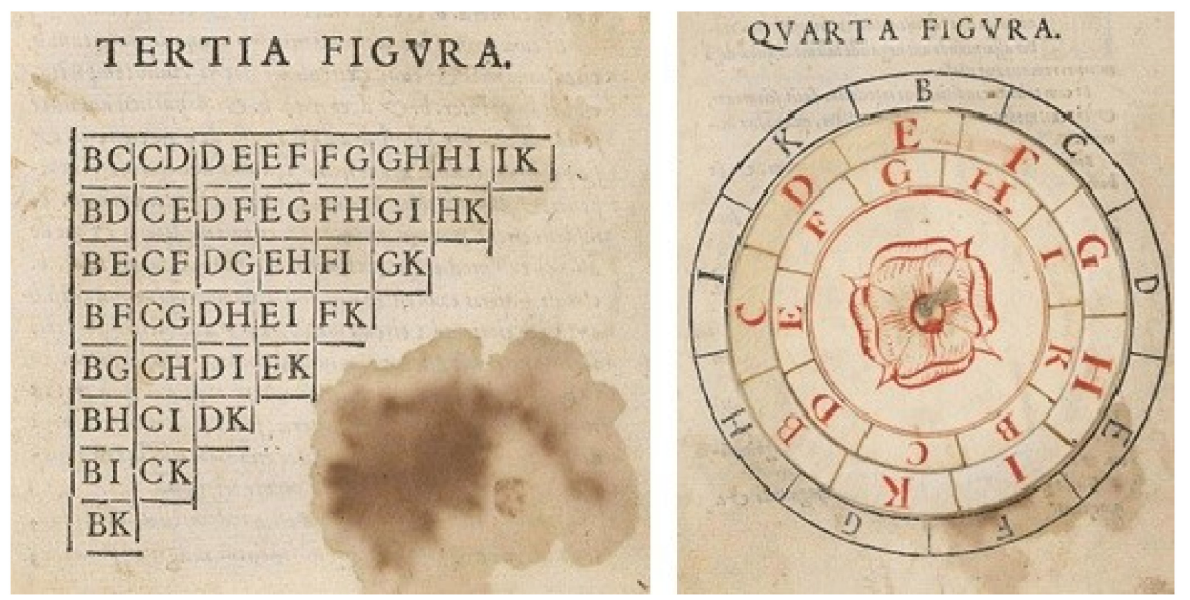

Figure 8. Tertia Figura (left) and Quarta Figura (right), most relevant for their encryption capabilities and undeniable contribution to cryptography. Source: https://plato.stanford.edu/entries/llull/ (accessed on 22 February 2021).

Llull was using his Ars Combinatoria as an instrument for decentralised governance. In the section dedicated to the teaching of the Ars, Llull notes his intention of his logic being an instrument to reason without appealing to authority. He writes in Ars Generalis Ultima 13-2:

"Second, he shall clearly explain the text to the students through reasoning, without any appeal to authority, and the students shall read through the text, and put any questions they have about it to the teacher." [27] Llull's first and only implementation of his decentralised governance system was in cities. He wrote a treaty named Liber Civitae Mundi, which would translate into English as The City of the World (the book is only available in its original version in Latin and Catalan at Badia [28]) where he exemplifies the use of the Ars Combinatoria in a societal environment. In the treaty he dramatizes a negotiation between what he calls the 7 Dignities (charity, hope, faith, temper, strength, prudence, justice) and the Council of Dignities, integrated by 14 Virtues (goodness, nobility, eternity, power, understanding, will, virtue, truth, glory, perfection, honour, compassion, grace, modesty), which will have to make a decision on whether or not to exterminate the city because of humans' poor behaviour. Importantly for blockchain technology, he included an instrument for delegated decision-making, the so-called The Jury of the Liber Civitae Mundi. Organisations created on the blockchain, some forms of the so-called DAOs include delegated decision-making through a vote. The 7 Dignities together with the Council of Dignities (the 14 Virtues) integrate the Jury of the City of the World. Each Virtue and Dignity are presented along with their own vices and temptations (following Llull's "opposites"). The Virtues act as Dignities' mediators and help them elaborate a decision (using Llull's combinatorial logic), resulting in the so-called Sentence of the City tod. The role of mediators is a pioneering form of delegation in order to achieve more informed and balanced decisions. Virtues mediation could even turn into Dignities delegating vote and decision making on them. This is a very advanced form of democracy, not yet contemplated in our legacy systems but present in blockchains' organisation protocols, namely in DAOs ran under Liquid Democracy code. 
Llull's Virtues delegated role are what in blockchain's Liquid democracy are called "representatives" and form the "House of Representatives". Further delegation is also possible under the so-called "Executive Branch". His Dignities in the Jury of the City of the World form the so-called "Congress" if acting on their own behalf (without delegated vote). Blockchains' notational combinatory logic is what makes the technology socially embedded [21] and, therefore, delegated, and this allows for physical civil intervention on issues that are typically deemed within the powers of state and institutions [29]. In total agreement with these authors, this presentation of the Cryptourbanomics method concludes that blockchain technology empowers citizens to self-address and self-manage challenges that the System has been unable to solve by giving them the digital tools to transform the traditional legacy mechanisms into citizen-led instruments. Indeed blockchain opens the possibility of new contractual options that will be worth exploring [30]. And, since blockchain allows for civil intervention on issues that are typically deemed within the powers of state and institutions, citizens will become the new intermediaries, able to empower civil society to run local public goods and services and facilitate economic and social entrepreneurship [31].

Inspired by this kind of "court mechanism" that Llull believes optimal to govern the City of the World, the Crytpourbanomics governance model is similarly designed: a Parliamentarian Jury of Virtues and Dignities will decide on the fate of a given urban cause. In this Parliamentarian Jury, Virtues and Dignities will take roles affecting the cause and these roles will be filled by institutions related to the cause. For example, in the cause used as an example, the Right to Work, the Parliamentarian Jury of Virtues and Dignities will be formed by Third Sector institutions (which includes both NGOs and CSOs) related to the Right to Work (labour unions, sectoral tables, employers' associations, etc.). These organisations will volunteer to oversee the agreements between parties by being one of the signatory parties. For instance, once there is a match between peers, that is one employer offering a position and that position being filled by an unemployed candidate, this agreement will be registered as a transaction in the Cryptourbanomics blockchain and this transaction will be a multi-signature three-party contract that will include the employer, the employee and the watchdog, who might also assist in the implementation of the agreement. Finally, as per the Cryptourbanomics method design, overseeing organisations will be only parties entitled to close a cause when deemed solved, similar to Llull's reductio ad impossible approach, they will issue Parliamentarian Proofs of Reductio ad Impossible to close a cause once solved.

\section{Conclusions}

Cryptourbanomics is a response to failed attempts to deliver on Urban Sustainability, the most recent example of this being Smart Cities initiatives. Cryptourbanomics begins by acknowledging the need for addressing causes that the System has been unable to solve, as important as Urban Sustainability. And, since blockchain is yet an anti-System technology, it is best placed to tackle those. But, once blockchain technology will be endorsed by the System, Cryptourbanomics will still remain relevant since its methodology consists of providing the missing connections that will allow for effective use of blockchains in the physical world, for instance, in urban environments. Therefore, and since the Cryptourbanomics method ultimately aims to give a response to Urban Sustainability, it provides the virtual-physical link for the three pillars of Urban Sustainability, social, economic and environmental. As seen with the cause used throughout the article as an example, the Right to Work, social sustainability is achieved by linking blockchain's decentralised governance capabilities with a bottom-up physical Parliament that uses Proof of Reductio ad impossible as a decision-making mechanism. Regarding economic sustainability, blockchain's distributed functionalities are used to physically implement the governance by creating a Public Agora dashboard to allocate and assign roles to solve the cause and its sub-causes. Lastly, these two elements of social decentralisation and economic distribution result in a third notation, that of disruptive ecology. In the 
ecological sustainability pillar, communities are maintained in their environments with the Ars Cryptocurrency, as a means to fix communities in their environments by introducing economic diversification and complexity through complementary currencies. Throughout the example of the Right to Work, Cryptourbanomics approach has demonstrated to be solvent in the three areas of Urban Sustainability, proving to be a trustworthy tool, not only for communities willing to tackle causes by themselves but for governments and private sector willing to finally address their long-lasting unsolved challenges.

Funding: This research received no external funding.

Institutional Review Board Statement: Not applicable.

Informed Consent Statement: Not applicable.

Conflicts of Interest: The author declares no conflict of interest.

\section{References}

1. Swan, M.; de Filippi, P. Toward a Philosophy of Blockchain: A Symposium: Introduction. Metaphilosophy 2017, 48, 603-619. [CrossRef]

2. Nordrum, A. Govern by Blockchain Dubai wants one platform to rule them all, while Illinois will try anything. IEEE Spectrum 2017, 54, 54-55. [CrossRef]

3. Huckle, S.; White, M. Socialism and the Blockchain. Future Internet 2016, 8, 49. [CrossRef]

4. Marsal-Llacuna, M.L.; Wood-Hill, M. The Intelligenter method (III) for "smarter" standards development and standardisation instruments. Comput. Stand. Interfaces 2016, 50, 142-152. [CrossRef]

5. Marsal-Llacuna, M.L.; Segal, M.E. The Intelligenter Method (II) for "smarter" urban policy-making and regulation drafting. Cities 2016, 61, 83-95. [CrossRef]

6. Marsal-Llacuna, M.L.; Segal, M.E. The Intelligenter Method (I) for making "smarter" city projects and plans. Cities 2016, 55, 127-138. [CrossRef]

7. Eiximenis, F. Regiment de la Cosa Pública; Cristòfor Cofman: Valencia, Spain, 1499; Available online: http:/ / www.estrategialocal com/_es/libros_y_manuales/_internal/repository/REGIMENT.pdf (accessed on 22 February 2021).

8. Wolfram, S. Cellular Automata and Complexity: Collected Papers; CRC Press, Taylor and Francis Group: Boca Raton, Florida, USA, 2018.

9. Conway, J. Game of Life. Sci. Am. 1970, 223, 120-123.

10. Chepurnoy, A.; Kharin, V.; Meshkov, D. Self-Reproducing Coins as Universal Turing Machine. In Proceedings of the ESORICS-CBT Workshop, Barcelona, Spain, 6-7 September 2018.

11. Margalef, R. Perspectives in Ecological Theory; University Chicago Press: Chicago, IL, USA, 1968.

12. Dos Santos, R.P. On the Philosophy of Bitcoin/Blockchain Technology: Is it a Chaotic, Complex System? Metaphylosophy 2017, 48, 620-633. [CrossRef]

13. Manski, S. Building the blockchain world: Technological commonwealth or just more of the same? Strateg. Change-Brief. Entrep. Financ. 2017, 26, 511-522. [CrossRef]

14. Albert, R.; Jeong, H.; Barabási, A.L. Error and attack tolerance of complex networks. Nature 2000, 406, 378-382. [CrossRef] [PubMed]

15. Solé, R.V.; Manrubia, S.C.; Benton, M.; Kauffman, S.; Bak, P. Criticality and scaling in evolutionary ecology. Perspectives 1999, 14, 156-160. [CrossRef]

16. Sun, J.; Yan, J.; Zhang, K.Z. Blockchain-based sharing services: What blockchain technology can contribute to smart cities. Financ. Innov. 2017, 2, 26. Available online: https://jfin-swufe.springeropen.com/articles/10.1186/s40854-016-0040-y (accessed on 22 February 2021). [CrossRef]

17. Saito, K.; Yamada, H. What's So Different about Blockchain? Blockchain is a Probabilistic State Machine. In Proceedings of the IEEE 36th International Conference on Distributed Computing Systems Workshops (ICDCSW), Nara, Japan, 27-30 June 2016; pp. $168-175$.

18. CNICCP. Ildefonso Cerdà 1815-1876: Catálogo de la Exposición Conmemorativa del Centenario de su Muerte; Colegio Nacional de Ingenieros de Caminos, Canales y Puertos, en Colaboración con Salvador Tarragó y Arturo Soria: Madrid, Spain, 1976.

19. Instituto Nacional de la Administración Pública and Ajuntament de Barcelona (Ed.) Teoría de la Construcción de las Ciudades: Cerdà y Barcelona; Instituto Nacional de la Administración Pública and Ajuntament de Barcelona: Barcelona, Spain, 1991 ; Volume 1.

20. Instituto de Estudios Fiscales (Ed.) Teoría General de la Urbanización y Aplicación de sus Principios y Doctrinas a la Reforma y Ensanche de Barcelona; Instituto de Estudios Fiscales: Madrid, Spain, 1968.

21. Dupont, Q. Blockchain Identities: Notational Technologies for Control and Management of Abstracted Entities. Metaphilosophy 2017, 48, 634-653. [CrossRef]

22. Vega, A. (Ed.) La Màquina de Pensar: Ramon Llull i l'ars Combinatoria; Diputació de Barcelona: Barcelona, Spain, 2016.

23. Eco, H. The Ars Magna by Ramon Llull. Contrib. Sci. 2016, 12, 47-50. 
24. Fidora, A.; Sierra, C. (Eds.) Ramon Llull: From the Ars Magna to Artificial Intelligence; Artificial Intelligence Research Institute, IIIA. Consejo Superior de Investigaciones Científicas: Barcelona, Spain, 2011.

25. Bonner, A. The Art and Logic of Ramon Llull: A User's Guide; English Version; Editorial Brill: Boston, MA, USA, 2007.

26. Künzel, W.; Cornelius, H. Die Ars Generalis Ultima des Raymundus Lullus; Studien zu Einem Geheimen Ursprung der Computertheorie: Berlin, Germany, 1991.

27. Stanford Encyclopaedia of Philosophy. Ramon Llull; Stanford University: Stanford, CA, USA, 2017; Available online: https: / / plato.stanford.edu/entries/llull/ (accessed on 22 February 2021).

28. Badia, L. El Fantàstic. La Ciutat del Món; Brepols Publishers: Turnhout-Santa Coloma de Queralt Universitat Rovira I Virgili: Tarragona, Spain, 2008.

29. Hughes, K. Blockchain, The Greater Good, and Human and Civil Rights. Metaphilosophy 2017, 48, 654-665. [CrossRef]

30. Wheeler, S. Visions of Contract. J. Law Soc. 2017, 44, 74-92. [CrossRef]

31. Potts, J.; Rennie, E.; Goldenfein, J. Blockchains and the crypto city. IT-Inf. Technol. 2017, 59, 286-293. [CrossRef] 